Reprinted from Hispanic Review, Vol. V, No. 4, October, 1937

Printed in U. S. A.

\title{
VARIA
}

\section{APUNTE CRONOLOGICO SOBRE EL ARENAL DE SEVILLA DE LOPE DE VEGA}

TaN incompleta está todavía la cronología de las comedias de Lope de Vega, a pesar de los eruditísimos estudios que se han hecho, y de tan vital importancia es para comprender y avalorar su obra, que me aventuro a publicar este apunte a riesgo de aparecer nimio.

Lope dío El arenal de Sevilla a la estampa en 1618 en la parte oncena de sus comedias. ${ }^{1}$ En varias ocasiones se ha tratado de fijar la fecha de composición de esta comedia con resultados más o menos satisfactorios. Chorley "advierte que debió ser compuesta después de enero de 1601, puesto que en el acto II (Rivad., XLI, 537 a), hay una referencia a la mudanza de la corte a Valladolid." ${ }^{2}$ Rennert ${ }^{3}$ repite la afirmación de Chorley, que Castro ${ }^{4}$ traduce sin añadidura alguna. García Soriano ${ }^{5}$ cree la comedia escrita de 1601 a 1604 . Heseler ${ }^{6}$ sugiere las fechas 1601 a 1603, que copia de Hämel. ${ }^{7}$ Buchanan, puntualizando un poco más, le asigna el año de 1603?, sin estar seguro de ello, como el signo de interrogación indica. ${ }^{8}$

Pues bien, la fecha de composición de El arenal de Sevilla es 1603, sin dudas de ninguna especie. El arenal de Sevilla fué escrito entre el 28 de febrero y el 17 de mayo de 1603.

He aquí mis razones. Entre los tantísimos personajes históricos mencionados en esta comedia, ${ }^{9}$ se hallan el conde de Niebla, que Lope dice ha sucedido al adelantado de Castilla en el mando de las galeras de

${ }^{1}$ Oncena parte de las comedias de Lope de Vega Carpio, familiar del Santo Oficio. Dirigidas a D. Bernabé de Vivanco y Velasco, caballero del hábito de Santiago, de la Cámara de Su Majestad. Sacadas de sus originales. Año 1618. Con privilegio. En Madrid, por la viuda de Alonso Martín de Balboa.

${ }^{2}$ H. A. Rennert y A. Castro, Vida, etc., Madrid, 1919, pág. 463.

${ }^{3}$ H. A. Rennert, Life, etc., Glasgow, 1904, pág. 495.

${ }^{4} \mathrm{H}$. A. Rennert y A. Castro, ibid.

${ }^{5}$ Acad. N., XI, xxv.

${ }^{6} \mathrm{M}$. Heseler, Studien zur Figur des gracioso bei Lope de Vega und Vorgängern, Hildesheim, 1933, pág. 126.

${ }^{7}$ A. Hämel, Studien zu Lope de Vegas Jugenddramen, etc., Halle, 1925, pág. 60.

${ }^{8}$ M. A. Buchanan, Chronology, etc., Toronto, 1922, pág. 19.

${ }^{9}$ El primer acto de la comedia está lleno de alusiones a personajes contemporáneos. Entre éstos se hallan los siguientes: don Jerónimo de Córdoba y Portugal; su padre, el Conde de Villar; el duque de Alba; don Francisco Duarte, y don Juan de Cardona. 
España; ${ }^{10}$ el marqués de Santa Cruz, a quien se le ha dado el mando de las galeras de Italia; ${ }^{11} \mathrm{y}$ a don Pedro de Toledo, que Lope dice no saldrá a caza de moros, pues piensa pasar a Milán. ${ }^{12}$

Si cotejamos estos datos con la historia, hallaremos que en Valladolid, a 28 de febrero de 1603 , se expidió título de capitán general de las galeras de España a favor de don Manuel Alonso Pérez de Guzmán el Bueno, conde Niebla. ${ }^{13}$ Poco después se nombró capitán general de la escuadra de Nápoles a don Alvaro Bazán, segundo Marqués de Santa Cruz. ${ }^{14}$ Este último nombramiento se susurraba ya a fines de enero. ${ }^{15}$ De don Pedro de Toledo nos dice Cabrera de Córdoba en relación fechada el 22 de febrero que ha sido "proveído por gobernador de Milán," con lo cual confirmamos el rumor que Lope recoge.

Lo más notable de estas alusiones históricas, y precisamente lo que nos lleva a sospechar que Lope escribiera El arenal de Sevilla antes del 17 de mayo es que él no menciona en ningún lugar a don Juan de Padilla Manrique de Acuña, conde de Santa Gadea, adelantado mayor de Castilla, hijo del difunto don Martín, a quien el conde de Niebla sucedió.

${ }^{10}$ Sobre el conde de Niebla véanse los siguientes versos:

\section{Castellanos}

Digo que es nueva muy cierta

que al conde de Niebla han hecho

general, y que sospecho

que jornada se concierta.

Fajardo

Sucede al Adelantado como nuevo sol que viene, que de su puesto sol tiene de ser el conde sol, dado . . .

Partióse el Adelantado,

y el conde se adelantó

${ }^{11}$ Sobre el marqués de Santa Cruz véanse los siguientes versos:

Fajardo

¿Quién a las de Italia viene?

Castellanos

No sé; mas tengo entendido

que vendrá el de Santa Cruz,

que tal rayo de la luz

${ }^{12}$ Sobre don Lope de Toledo véanse los siguientes versos:

Castellanos

Suspenso quedo

de no ver al gran Toledo ...

Fajardo

. . Si don Pedro de Toledo

volviere, ya vos sabéis por llegar donde llego

el sol de tan gran soldado.

De tal Niebla sale el sol, que el Africa, aunque abrasada, teme el rayo de la espada del nuevo conde español; que la espada del Padilla que la solía allanar, dí al pez espada del mar en herencia esta cuchilla.

(H. III, 531 a)

${ }^{13}$ C. Fernández D

de su muerto padre ha sido; aquel heróico Bazán, que en la gran casa del Viso que hablen las paredes quiso

(H. III, 531 b)

${ }^{14}$ Ibid.

${ }^{15}$ Cabrera de Córdoba, Relaciones, etc., Madrid, 1857, pág. 166.

que nos honra. ¿Qué teméis? Castellanos

A la opinión tengo miedo don Pedro no ha de volver; que dicen que va a Milán.

(H. III, 531, b, c) 
El joven adelantado fué nombrado general de las galeras de Sicilia como Cabrera de Córdoba dice en Relación fechada el 17 de mayo de 1603.

¿Por qué no menciona Lope al joven adelantado después de haber colmado de alabanzas a su padre? Sencillamente porque su nombramiento no había sido publicado. De este modo podemos inferir justamente que El arenal de Sevilla fué compuesto en abril o durante los primeros diez y siete días de mayo del 1603.

$\mathrm{Si}$ a pesar de todos los datos aducidos se dudara aún de la fecha de esta comedia de Lope, recordemos que él la menciona en la primera lista del Peregrino, y que la dedicatoria de esta novela fué escrita el 31 de diciembre de 1603 , por lo que podemos afirmar categóricamente que El arenal de Sevilla fué escrita en 1603.

J. H. ArJona

Connecticut State College 